\title{
What about Th1/Th2 in cutaneous leishmaniasis vaccine discovery?
}

\section{A. Campos-Neto}

Correspondence

A. Campos-Neto

The Forsyth Institute

140 The Fenway

Boston, MA 02115-3799

USA

Fax: +1-617-892-8326

E-mail: acampos@forsyth.org

......................

Received January 4, 2005

Accepted March 18, 2005
The Forsyth Institute, Boston, MA, USA

\begin{abstract}
The T helper cell type 1 (Th1) response is essential to resist leishmaniasis, whereas the Th2 response favors the disease. However, many leishmanial antigens, which stimulate a Th1 immune response during the disease or even after the disease is cured, have been shown to have no protective action. Paradoxically, antigens associated with an early Th2 response have been found to be highly protective if the Th1 response to them is generated before infection. Therefore, finding disease-associated Th 2 antigens and inducing a Th1 immune response to them using defined vaccination protocols is an interesting unorthodox alternative approach to the discovery of a leishmania vaccine.
\end{abstract}

Key words

- Leishmania

- Th1/Th2 paradigm

- Infection

- Vaccine

- Antigen discovery

- Adjuvant

.....................

\section{Introduction}

$\mathrm{T}$ cells mediate acquired resistance to leishmaniasis. This notion has been supported by classical experiments which established that $\mathrm{T}$ cell-deficient mice rapidly succumb after inoculation with any one of several species of Leishmania, and that transfer of normal $\mathrm{T}$ cells confers resistance to the animals (1-3). The $\mathrm{CD}^{+}$subset of $\mathrm{T}$ cells is crucial for resistance, whereas $\mathrm{CD} 8^{+} \mathrm{T}$ cells seem to participate more in the memory events of the immune response than as effector cells involved in parasite elimination. However, recent studies have suggested that $\mathrm{CD}^{+} \mathrm{T}$ cells are also involved in the clearance of primary infection. These conclusions were reached on the basis of a series of elegant experiments using mice genetically engineered to lack either major histocompatibility complex (MHC) class I or class II molecules, or mice lacking $\mathrm{CD}^{+}$or $\mathrm{CD} 8^{+} \mathrm{T}$ cells (4-11).

In addition, the murine model has been extremely helpful for the understanding of the genetic mechanism of protection conferred by $\mathrm{T}$ cells. Most inbred mouse strains (e.g., C57BL/6, CBA/J, C3H, B10D2) are resistant to infection with Leishmania major. Upon intradermal/sub-cutaneous injection with $L$. major, these animals develop a small lesion that subsides within 6-8 weeks. By contrast, BALB/c mice are highly susceptible to infection with these organisms $(12,13)$. These mice fail to control the infection and develop extensive lesions. The parasites metastasize to the internal viscera (primarily liver, spleen, and bone marrow), an event that may lead to the animal's death. Many different genes spanning the mouse genome have been implicated in susceptibility/resistance to Leishmania. Most of these genes do not map within the MHC systems of either humans or mice, including the SCL1 gene implicated in the high susceptibility of $\mathrm{BALB} / \mathrm{c}$ mice to infection with L. major (14).

However, one of the most striking concepts arising from these studies is the clear association of resistance and susceptibility with the emergence of the two phenotypi- 
cally distinct subsets of $\mathrm{CD} 4^{+} \mathrm{T}$ cells, namely T helper cell type 1 (Th1) and type 2 (Th2) cells, during the disease process. Upon infection with $L$. major, mice of the resistant phenotype clearly develop a dominant Th1 phenotype of immune response to the parasite's antigens. By contrast, BALB/c mice develop a typical Th2 response. Several systems have been used to correlate resistance/susceptibility with Th1/Th2 responses but perhaps the most compelling one is that involving mice genetically deficient in either interferon $\gamma$ (IFN- $\gamma$ ) or interleukin 4 (IL-4), the phenotypic surrogates of the Th1 and Th2 $\mathrm{CD}^{+} \mathrm{T}$ cell responses, respectively. Thus, targeted disruption of the IFN- $\gamma$ gene in C57BL/6 mice causes these animals, which are otherwise resistant to infection with $L$. major, to become highly susceptible to these organisms $(15,16)$. Moreover, IL-4 transgenic resistant mice expressing low levels of this cytokine fail to clear the infection $(17,18)$. In addition, targeted disruption of the IL-4 gene in BALB/c mice causes these animals, which are otherwise susceptible to infection with $L$. major, to become highly resistant to these organisms (19). However (and surprisingly), genetic disruption of the IL-4 gene of BALB/c mice can also generate animals that are as susceptible to infection with $L$. major as are wildtype conventional BALB/c mice (20). The reasons for this discrepancy depend on some circumstances such as infection with particular L. major sub-strains, due to the fact that IL-4 and/or IL-4 receptor signaling is not required to promote Th2 cell development and susceptibility in BALB/c mice (21).

More recently, susceptibility and resistance to Leishmania infection in the mouse model have also been demonstrated to be associated with the emergence of a unique subset of $\mathrm{T}$ cells, namely the $\mathrm{T}$ regulatory cells ( $\mathrm{T}$ reg) and with the levels of the cytokine IL-10 (22,23). T reg cells $\left(\mathrm{CD}^{+}\right.$ $\mathrm{CD} 25^{+}$) suppress the activity of effector $\mathrm{T}$ cell populations $\left(\mathrm{CD} 4^{+} \mathrm{CD} 25^{-}\right)$specific for self-antigens as well as foreign invaders such as leishmania parasites. Interestingly, during infection of C57BL/6 mice with L. major, $\mathrm{CD} 4{ }^{+} \mathrm{CD} 25^{+} \mathrm{T}$ cells accumulate in the leishmanial skin lesions, and these cells produce IL-10 upon in vitro stimulation with parasite antigens. IL-10 is a potent inhibitor of IFN- $\gamma$ production and has been shown to be a key cytokine that favors the persistence of the parasites in skin lesions (24). Therefore, T reg cells and IL-10 are important and integrated mediators or regulators of resistance/susceptibility to leishmaniasis.

\section{Premises concerning Th1/Th2 in vaccine development}

During the past decade, several investigators have used the Th1/Th2 paradigm to construct a syllogism that supports a strategy of antigen discovery/selection in vaccine development against leishmaniasis. Thus, leishmanial antigens that predominantly stimulate Th1 responses in patient cells or spleen or lymph node cells from mice infected with $L$. major have commonly been accepted as "potential protective antigens" and therefore promising vaccine candidates. Conversely, antigens that predominantly stimulate a Th2 response from these cells have been regarded as of lesser interest as vaccine candidates because they are likely to be associated with pathology.

Paradoxically with respect to the conventional Th1/Th2 paradigm, many investigators have observed that several leishmanial antigens against which a Th1 response is developed during the infection are not necessarily protective antigens. For example, lymph node cells of BALB/c mice chronically infected with $L$. major, upon stimulation with the Ldp23 antigen produce high levels of IFN- $\gamma$ and undetectable amounts of IL-4, a typical Th1 response (25). However, immunization of BALB/c mice with Ldp23 in combination with adjuvants that preferentially induce Th1 responses, such as IL-12 
and monophosphoryl lipid A plus squalene (MPL-SE), despite stimulating a strong antigen-specific Th1 response in the absence of any detectable Th2 response, results in no protection (26). This lack of correlation with protection was also observed with eight other leishmanial antigens that have been discovered and selected on the basis of the Th1/ Th2 paradigm and using peripheral blood mononuclear cells from cured leishmaniasis patients as immunological readouts $(26,27)$.

In clear contrast, the LACK antigen stimulates a strong Th2 response that can be detected in lymph node and spleen cells soon after infection of $\mathrm{BALB} / \mathrm{c}$ mice with $L$. major. In addition, the sera of these animals contain high titers of IgG1 anti-LACK antibodies. In spite of this, LACK induces substantial protection in $\mathrm{BALB} / \mathrm{c}$ mice if administered in conjunction with adjuvants that stimulate Th1 responses $(28,29)$. More recently, a Leishmania mexicana cysteine protease antigen named CPB2.8 was shown to be a potent Th2-inducing molecule during experimental leishmaniasis but, similarly to LACK, capable of inducing significant protection if administered with Th1-modulating adjuvants (30).

In another situation, the LmSTI1 antigen stimulates mixed Th1/Th2 responses in lymph node cells of BALB/c mice infected with $L$. major and the sera of these animals contain high titers of $\operatorname{IgE}, \operatorname{IgG} 1$, and $\operatorname{IgG} 2 \mathrm{a}$ anti-LmSTI1 antibodies (31). As is the case for LACK, LmSTI1 is readily recognized by the mouse lymph node and spleen cells soon after infection. Moreover, LmSTI1 induces excellent protection in $\mathrm{BALB} / \mathrm{c}$ mice and in monkeys if used with IL-12 (32) or MPL-SE (33) as adjuvant. Interestingly, these two antigens (LACK and LmSTI1) do not share sequence similarities and yet are equally involved in stimulating primarily a Th2 response during the infectious process caused by $L$. major in BALB/c mice. Therefore, it seems that the biased Th2 response is not dependent on a particular molecular characteristic of leishmanial antigens.
Moreover, recent experiments using the avirulent mutant phosphoglycan-deficient $L$. major (lpg2-parasites) demonstrated that infection of mice with this parasite results in minor disease and long survival of the mutant in the animals' tissues. Interestingly, for reasons not yet understood, lymph node cells from the mice infected with this mutant, in contrast to mice infected with wild-type parasites, produced minimal levels of IL-4 and IL10 after in vitro stimulation with $L$. major soluble antigens. However, the levels of IFN$\gamma$ produced by the cells of mice infected with the mutant were only slightly lower than the levels of IFN- $\gamma$ produced by the lymph node cells of mice infected with wild-type L. major. Not surprisingly, vaccination of $B A L B / c$ mice with lpg2-parasites conferred excellent protection against challenge with virulent organisms (34). In conclusion, the protection induced by lpg2-parasites is basically not associated with enhanced IFN- $\gamma$ production in response to leishmanial antigens but clearly with a dramatic suppression of IL-4 and IL-10 responses to the same antigens.

It is clear that these results do not support the use of Th1 cells from infected hosts as readouts for antigen selection in vaccine development against leishmaniasis. However, they by no means challenge the concept that a Th1 response is essential for protection against leishmaniasis. Indeed, as mentioned above, inducing a Th1 immune response to LACK before infection results in protection $(28,29)$. Conversely, immunization of BALB/c mice with LmSTI1 formulated with alum, an adjuvant that polarizes the immune response to Th2 phenotype, results in no protection, in clear contrast to immunization with the IL-12 adjuvant (35).

\section{An alternative Th1/Th2 premise}

We conclude from these arguments that for vaccine development against leishmaniasis, the use of immunological mediators of polarized Th1-specific immune response to 
parasite antigens as readouts for antigen discovery and selection seems to be redundant and irrelevant. Rather, potent Th2-inducing antigens that are expressed or secreted by the parasites after infection (particularly during the initiation of the infection) seem to be more appropriate target molecules for vaccine development, as long as they are administered with an adjuvant that, in combination with them, modulates a strong Th1 response, thus preventing the emergence of disease favoring antigen-specific Th 2 clones (Figure 1). Indeed, once Th1 cells are triggered for a particular antigen a memory is generated and a future infectious process will restimulate these Th1 memory cells instead of possible Th2 responses that would normally emerge if the memory had not been previously established (36). In other words, offsetting the parasite's Th2 strategies instead of fostering the Th1 response that is elicited during infection can be an efficient alternative in vaccine development against leishmaniasis.

Unfortunately, at this time, despite the fact that evaluation of antigen immunogenicity during later phases of the infectious process (e.g., 2-3 weeks post-infection) can be easily achieved, the evaluation and selection (discovery) of antigens that stimulate the immune response immediately after the initiation of the infection is a rather difficult task. However, T cell lines can be generated from lymph node cells of mice as early as 23 days post-infection, thus opening the possibility to use them in gene cloning strategies as readouts of the pathogen's cDNA or genomic expression libraries $(27,33)$. This approach should permit the identification or discovery of dominant Th1 or Th2 parasite antigens that are expressed immediately after the initiation of the infectious process.

A constraint of this proposed unorthodox alternative is that it relies primarily on the unique Th1/Th2 paradigm of the mouse model of leishmaniasis. As already mentioned, recent evidence suggests that leishmanial antigens stimulate $\mathrm{T}$ reg cells $\left(\mathrm{CD} 4{ }^{+} \mathrm{CD} 25^{+}\right)$, thus impairing the activation of the effector $\mathrm{CD}^{+}{ }^{+} \mathrm{CD} 25^{-} \mathrm{T}$ cells. Therefore, under these circumstances such antigens are not necessarily associated with the classical Th1/Th2 pathways of regulation of resistance/susceptibility and would theoretically be missed by strategies designed to detect Th2-inducing antigens. However, the
Figure 1. Schematic illustration of a common sense Th1 strategy (upper box) and an unorthodox Th2 alternative protocol (lower box) of antigen discovery/ selection in vaccine development against cutaneous leishmaniasis. IL-12 = interleukin 12; MPL-SE = monophosphoryl lipid A plus squalene.

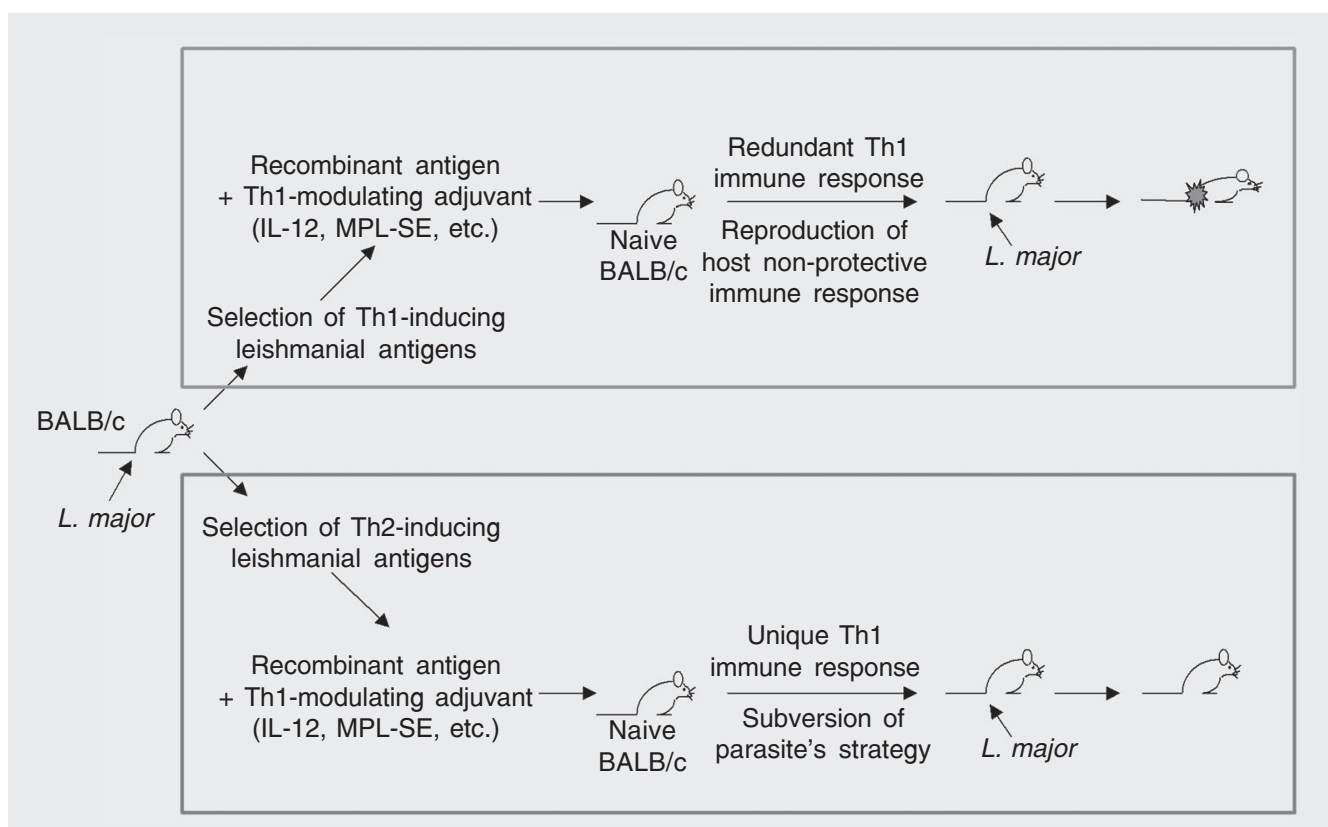


T cell-cloning strategy can be easily adapted for the detection of IL-10-inducing antigens. Therefore, the parasite's genes encoding such antigens can be cloned and expressed and theoretically used, similarly to Th2-inducing antigens, in immunization protocols that offset their ability to induce IL-10. A second constraint of our proposal is that it may not be applicable to humans because the Th1/ Th2 paradigm is not as strongly supported in humans as it is in the murine model of leishmaniasis. However, although circumstantial, evidence does suggest that resistance and susceptibility to cutaneous leishmaniasis may be associated with the Th1 phenotype of the immune response in humans as well $(37,38)$. A third possible constraint of the proposal is that the singularity of the high susceptibility of BALB/c animals to infection with $L$. major may not reflect the general susceptibility of humans, particularly patients with cutaneous leishmaniasis in the "Old World". Resistant mice (e.g., C57BL/6) may perhaps reflect better the clinical response of humans to this parasite and other self-limiting leishmania infections. In contrast, the BALB/c model perhaps reflects better the clinical response of some non-self healing patients with "New World" leishmaniasis. However, the use of the more susceptible animal models seems appropriate because they mirror more closely the immunological status of the individuals in the human population who are ultimately the targets of the vaccine, i.e., the susceptible and not the resistant or self-healing individuals.

Thus, we conclude that, apart from these listed constraints, a pragmatic approach to the development of a vaccine against leishmania infection, and perhaps against other intracellular infectious organisms, is to prioritize antigens based on potency and on the Th2 phenotype of the immune response that is generated against them immediately after the initiation of the infection. At least theoretically, the most immunogenic Th2 antigens during the early phases of the infectious process should be the most readily available and perhaps most abundant targets for protection upon a vaccination regime that primes a solid and sustained Th1 response to them. In other words, offsetting the parasite's Th2 strategies instead of fostering the Th1 response that is elicited during infection can be an efficient alternative in vaccine development against leishmaniasis and other pathogens.

Indeed, using a similar criterion, we have identified a Mycobacterium tuberculosis protein which is a promising candidate for a recombinant antigen vaccine against tuberculosis (39).

\section{References}

1. Handman E, Ceredig R \& Mitchell GF (1979). Murine cutaneous leishmaniasis: disease patterns in intact and nude mice of various genotypes and examination of some differences between normal and infected macrophages. Australian Journal of Experimental Biology and Medical Science, 57: 9-29.

2. Preston PM, Carter RL, Leuchars E, Davies AJ \& Dumonde DC (1972). Experimental cutaneous leishmaniasis. 3. Effects of thymectomy on the course of infection of CBA mice with Leishmania tropica. Clinical and Experimental Immunology, 10: 337-357.

3. Scott P, Natovitz P, Coffman RL, Pearce E \& Sher A (1988). Immunoregulation of cutaneous leishmaniasis. $T$ cell lines that transfer protective immunity or exacerbation belong to different $T$ helper subsets and respond to distinct parasite antigens. Journal of Experimental Medicine, 168: 1675-1684.

4. Fowell DJ, Magram J, Turck CW, Killeen N \& Locksley RM (1997).
Impaired Th2 subset development in the absence of Cd4. Immunity, 6: 559-569.

5. Erb K, Blank C, Ritter U, Bluethmann H \& Moll H (1996). Leishmania major infection in major histocompatibility complex class II-deficient mice: CD8+ T cells do not mediate a protective immune response. Immunobiology, 195: 243-260.

6. Chakkalath HR, Theodos CM, Markowitz JS, Grusby MJ, Glimcher LH \& Titus RG (1995). Class II major histocompatibility complexdeficient mice initially control an infection with Leishmania major but succumb to the disease. Journal of Infectious Diseases, 171: 13021308.

7. Overath P \& Harbecke D (1993). Course of leishmania infection in beta 2-microglobulin-deficient mice. Immunology Letters, 37: 13-17.

8. Rhee EG, Mendez S, Shah JA et al. (2002). Vaccination with heatkilled leishmania antigen or recombinant leishmanial protein and 
Cpg oligodeoxynucleotides induces long-term memory CD4+ and CD8+ $\mathrm{T}$ cell responses and protection against Leishmania major infection. Journal of Experimental Medicine, 195: 1565-1573.

9. Belkaid Y, Von Stebut E, Mendez S, Lira R, Caler E, Bertholet S, Udey MC \& Sacks D (2002). CD8+ T cells are required for primary immunity in C57BL/6 mice following low-dose, intradermal challenge with Leishmania major. Journal of Immunology, 168: 39924000.

10. Huber M, Timms E, Mak TW, Rollinghoff M \& Lohoff M (1998). Effective and long-lasting immunity against the parasite Leishmania major in CD8-deficient mice. Infection and Immunity, 66: 3968-3970.

11. Locksley RM, Reiner SL, Hatam F, Littman DR \& Killeen N (1993). Helper T cells without CD4: control of leishmaniasis in CD4-deficient mice. Science, 261: 1448-1451.

12. Launois P, Tacchini-Cottier F, Parra-Lopez C \& Louis JA (1998). Cytokines in parasitic diseases: the example of cutaneous leishmaniasis. International Reviews of Immunology, 17: 157-180.

13. Scott $P$ (1998). Differentiation, regulation and death of $T$ helper cell subsets during infection with Leishmania major. Immunologic Research, 17: 229-238.

14. Blackwell JM (1996). Genetic susceptibility to leishmanial infections: studies in mice and man. Parasitology, 112 (Suppl): S67-S74.

15. Swihart K, Fruth $U$, Messmer N, Hug K, Behin R, Huang $S$, Del Giudice G, Aguet M \& Louis JA (1995). Mice from a genetically resistant background lacking the interferon gamma receptor are susceptible to infection with Leishmania major but mount a polarized $\mathrm{T}$ helper cell 1-type CD4+ T cell response. Journal of Experimental Medicine, 181: 961-971.

16. Wang ZE, Reiner SL, Zheng S, Dalton DK \& Locksley RM (1994). CD4+ effector cells default to the Th2 pathway in interferon gammadeficient mice infected with Leishmania major. Journal of Experimental Medicine, 179: 1367-1371.

17. Erb KJ, Blank C \& Moll H (1996). Susceptibility to Leishmania major in IL-4 transgenic mice is not correlated with the lack of a Th1 immune response. Immunology and Cell Biology, 74: 239-244.

18. Leal LM, Moss DW, Kuhn R, Muller W \& Liew FY (1993). Interleukin4 transgenic mice of resistant background are susceptible to Leishmania major infection. European Journal of Immunology, 23: 566569.

19. Kopf M, Brombacher F, Kohler G, Kienzle G, Widmann KH, Lefrang K, Humborg C, Ledermann B \& Solbach W (1996). IL-4-deficient BALB/c mice resist infection with Leishmania major. Journal of Experimental Medicine, 184: 1127-1136.

20. Noben-Trauth N, Kropf P \& Muller I (1996). Susceptibility to Leishmania major infection in interleukin-4-deficient mice. Science, 271: 987-990.

21. Sacks D \& Noben-Trauth N (2002). The immunology of susceptibility and resistance to Leishmania major in mice. Nature Reviews. Immunology, 2: 845-858.

22. Kane MM \& Mosser DM (2001). The role of IL-10 in promoting disease progression in leishmaniasis. Journal of Immunology, 166: 1141-1147.

23. Belkaid Y, Piccirillo CA, Mendez S, Shevach EM \& Sacks DL (2002). $\mathrm{CD} 4+\mathrm{CD} 25+$ regulatory $\mathrm{T}$ cells control Leishmania major persistence and immunity. Nature, 420: 502-507.

24. Belkaid Y, Hoffmann KF, Mendez S, Kamhawi S, Udey MC, Wynn TA \& Sacks DL (2001). The role of interleukin (IL)-10 in the persistence of Leishmania major in the skin after healing and the therapeutic potential of anti-IL-10 receptor antibody for sterile cure. Journal of Experimental Medicine, 194: 1497-1506.

25. Campos-Neto A, Soong L, Cordova JL, Sant'angelo D, Skeiky YA, Ruddle NH, Reed SG, Janeway Jr C \& Mcmahon-Pratt D (1995).
Cloning and expression of a Leishmania donovani gene instructed by a peptide isolated from major histocompatibility complex class II molecules of infected macrophages. Journal of Experimental Medicine, 182: 1423-1433.

26. Campos-Neto A (2002). Anti-leishmania vaccine. In: Farrel JP (Editor), Leishmania. Vol. 4. Kluwer Academic Publishers, Boston, MA, USA, 169-190.

27. Probst $P$, Stromberg E, Ghalib HW, Mozel M, Badaro R, Reed SG \& Webb JR (2001). Identification and characterization of T cell-stimulating antigens from Leishmania by CD4 T cell expression cloning. Journal of Immunology, 166: 498-505.

28. Mougneau E, Altare F, Wakil AE, Zheng S, Coppola T, Wang ZE, Waldmann R, Locksley RM \& Glaichenhaus N (1995). Expression cloning of a protective leishmania antigen. Science, 268: 563-566.

29. Julia V, Rassoulzadegan M \& Glaichenhaus N (1996). Resistance to Leishmania major induced by tolerance to a single antigen. Science, 274: 421-423.

30. Pollock KG, McNeil KS, Mottram JC, Lyons RE, Brewer JM, Scott P, Coombs GH \& Alexander J (2003). The Leishmania mexicana cysteine protease, CPB2.8, induces potent Th2 responses. Journal of Immunology, 170: 1746-1753.

31. Webb JR, Kaufmann D, Campos-Neto A \& Reed SG (1996). Molecular cloning of a novel protein antigen of Leishmania major that elicits a potent immune response in experimental murine leishmaniasis. Journal of Immunology, 157: 5034-5041.

32. Campos-Neto A, Porrozzi R, Greeson K, Coler RN, Webb JR, Skeiky YA, Reed SG \& Grimaldi Jr G (2001). Protection against cutaneous leishmaniasis induced by recombinant antigens in murine and nonhuman primate models of the human disease. Infection and Immunity, 69: 4103-4108.

33. Skeiky YA, Coler RN, Brannon M, Stromberg E, Greeson K, Crane RT, Webb JR, Campos-Neto A \& Reed SG (2002). Protective efficacy of a tandemly linked, multi-subunit recombinant leishmanial vaccine (Leish-111f) formulated in Mpl adjuvant. Vaccine, 20: 32923303.

34. Uzonna JE, Spath GF, Beverley SM \& Scott P (2004). Vaccination with phosphoglycan-deficient Leishmania major protects highly susceptible mice from virulent challenge without inducing a strong Th1 response. Journal of Immunology, 172: 3793-3797.

35. Reed SG, Coler RN \& Campos-Neto A (2003). Development of a leishmaniasis vaccine: the importance of Mpl. Expert Review of Vaccines, 2: 239-252.

36. Stobie L, Gurunathan S, Prussin C, Sacks DL, Glaichenhaus N, Wu CY \& Seder RA (2000). The role of antigen and IL-12 in sustaining Th1 memory cells in vivo: IL-12 is required to maintain memory/ effector Th1 cells sufficient to mediate protection to an infectious parasite challenge. Proceedings of the National Academy of Sciences, USA, 97: 8427-8432.

37. Caceres-Dittmar G, Tapia FJ, Sanchez MA, Yamamura M, Uyemura K, Modlin RL, Bloom BR \& Convit J (1993). Determination of the cytokine profile in American cutaneous leishmaniasis using the polymerase chain reaction. Clinical and Experimental Immunology, 91: 500-505.

38. Pirmez C, Yamamura M, Uyemura K, Paes-Oliveira M, ConceicaoSilva F \& Modlin RL (1993). Cytokine patterns in the pathogenesis of human leishmaniasis. Journal of Clinical Investigation, 91: 13901395.

39. Skeiky YA, Ovendale PJ, Jen S, Alderson MR, Dillon DC, Smith S, Wilson CB, Orme IM, Reed SG \& Campos-Neto A (2000). T cell expression cloning of a Mycobacterium tuberculosis gene encoding a protective antigen associated with the early control of infection. Journal of Immunology, 165: 7140-7149. 